\title{
Mediated Massacre: Digital Nationalism and History Discourse on China's Web
}

\section{Florian Schneider}

\begin{abstract}
On China's web, networked actors ranging from state agencies to private internet users engage in highly active online discourse. Yet as diverse as this discourse may be, political content remains highly regulated, particularly on issues that affect the legitimacy of the ruling Party. A prominent issue in this regard has been modern Chinese history, particularly the 'national humiliation' that Japan inflicted on China's populace during events like the 1937 Nanjing Massacre. This article asks how the discourse on this particular event is structured on China's web, and what such practices of digital 'remembering' can tell us about nationalism in the information age. Combining content analysis and digital tools, the article shows how the mass-media model that the Chinese authorities and various commercial actors apply to the web ultimately reproduces the very logic of 'imagined communities' that makes reconciliation of historical disputes in East Asia so protracted.
\end{abstract}

\section{Keywords}

China; Chinese internet; collective remembering; digital media; historiography; imagined communities; Nanjing Massacre; nationalism; online discourse; Sino-Japanese history 


\section{Affiliation}

Florian Schneider (f.a.schneider@hum.leidenuniv.nl) is University Lecturer in the Politics of Modern China at the Leiden University Institute for Area Studies. 


\section{Introduction}

In East Asia, politics and international relations are closely tied to differing interpretations of the region's modern history, in particular imperial Japan's legacy of war. Whether it is conflicts over history textbooks (Saaler 2005), political rituals and symbols (Kingston 2007), or contested territories (Hagström 2012), relations in the region remain deeply affected by history discourses (He 2007; Gustafsson 2014). In China, for instance, perceived offenses by Japanese politicians against the Chinese nation and its memory of World War II have repeatedly caused outrage, which has at times spilled into the streets as public protest (Wallace \& Weiss 2015).

An important dimension of these conflicts over East Asian history is how media shape history discourse. Authors who have examined mainstream media in China (Zhang 2014) and Japan (Suzuki \& Murai 2014) have found that prominent media outlets generally frame the issue in nationalist terms that resonate with conservative audiences while simultaneously legitimating the ruling elites. Yet mainstream mass-media are no longer the only information sources available. Digital media have changed how meaning-making works in contemporary societies. For the Chinese case, a wealth of scholarship has shown how digital technologies like mobile phones (Liu 2014), blogs (Esarey \& Qiang 2008), and microblogging services (Tong \& Zuo 2014) have contributed to cultural, social, and political diversity (also cf. Yang 2009, Zheng 2008, and the contributions in Herold \& Marolt 2011). Yet controversies over modern history suggest that digital media do not unequivocally play a positive role in the politics of contemporary nation-states. When it comes to East Asian 
history and politics, China's internet is frequently dominated by aggressively nationalist zeal (Leibold 2010) that threatens to drown out more conciliatory voices and that has become a major factor in regional politics and international relations (cf. Gries et al. 2016, Reilly 2012, and the contributions in Shen \& Breslin 2010).

How are nationalism and history connected through digital media, and in what ways do the features that are native to the digital (e.g. hyperlinks, search algorithms, or social media buttons, cf. Rogers 2013) affect how stakeholders in a specific society construct a sense of a shared past? To explore these questions, this article examines how history is presented on China's web, using the case of a crucial topic in contemporary Chinese historiography: the Nanjing Massacre (cf. the contributions in Fogel 2000). The event marks a particularly gruesome episode of the Second Sino-Japanese War, and the atrocities that the Japanese invaders committed during their occupation of China's former capital city in the winter of 1937 have been central to patriotic education in the PRC (He 2007), for instance in school curricula (Wang 2012: ch.4) and museum exhibits (Denton 2014: ch.6). As Callahan (2010: 165) puts it: "the "rape" of Nanjing defines the relationship between China and Japan'.

The article starts with a discussion of how history and media are connected in modern nation-states. The subsequent study will be media-centric, meaning that it will follow the medium to explore how design choices and technical affordances shape discourse. Digital media possess an in-built 'hypermediality' (Bolter \& Grusin 2000), meaning that they combine different, often interactive modes of communication, and this hypermediality has 
often been assumed to facilitate serendipity (Manovich 2001: 76) or even hold radically emancipatory potential (O’Sullivan 2011). To check what effects the web's hypermediality has on history discourses in the PRC, the article covers four different aspects of how the Nanjing Massacre is today mediated through China's web. This includes the roles that Chinese search engines play as entryways into the subject, and that allied online encyclopaedias play as information sources. The article then examines how major Chinese websites and their digital features contribute to the Nanjing Massacre discourse online, as well as how the issue is embedded in online hyperlink networks. As this study shows, the web can be configured according to different 'media logics' (Chadwick 2013: 175), in this case collapsing complexities and promoting unified narratives that resemble those promoted through the PRC's traditional mass media.

\section{How Imagined Communities Construct their Collective Past}

How might we think of discourses, power, and collective remembering in societies where digital communication is becoming ubiquitous? Such dynamics are best understood by taking the medium seriously: digital media now frequently sit between us and our knowledge of the world, 'filtering' how we perceive and evaluate the complexities that surround us (Pariser 2012: 237). David Berry (2011: 18) makes the case that we need to 'think critically about how knowledge in the 21 st century is transformed into information through computational techniques'. Importantly, the degree to which the users of information and communication 
technologies (ICT) participate in online discourses raises the question of whether the control that traditional institutions like states and corporate media exert over knowledge construction is becoming too costly or complex to maintain (cf. Benkler 2006).

An organization that is heavily affected by this ostensible opening-up of political discourse is the nation-state. The nation-state is a political technology designed to solve a specific problem of the modern condition: how to arrange the complexity of social life in a way that makes large-scale political and economic organization possible (Gellner 1983/2006: 5). It is a form of political organization that takes the pre-modern concept of the 'state' (i.e. a collection of political institutions that claim a legitimate monopoly on the power to govern a territory) and makes it coterminous with the idea of the 'nation' (a set of people who see themselves as part of a larger ethnic community, based on perceived cultural, linguistic, civic, and/or physiological commonalities; cf. Shapiro 2004: 49).

This fusion of politics and culture may today seems natural, almost primordial, but it is the result of a lengthy process of construction, innovation, and negotiation. A fundamental force behind the nation-state is the ability of diverse actors to deploy mediated symbolic and discursive resources to inspire a personal investment in the idea of the nation and its political sovereignty. Such an investment leverages the idiosyncrasies of social psychology to create the cognitive foundation for the nation (Billig 2009: 10): nationalism. Nationalism is a framework of thought that taps into the human aspiration to feel a sense of 'belonging' or 'home' (cf. Guibernau 2013). We should consequently view nationalism as parasitic of the 
psychological mechanisms that generally inform group association, only that nationalism attaches these mechanisms specifically to the socially constructed entity of the nation.

What sets the belief in nation-ness apart from affiliations with smaller, face-to-face groups is that the nation constitutes, as Anderson (2006) famously phrased it, an 'imagined community': its members do not personally know each other, yet they perceive a set of cultural artefacts and social practices to be 'shared' within their group. ${ }^{1}$ Guibernau (2004: 134) has stressed that this sense of community relies on the subjective feelings of its members that they share a common past. Control over the past is a crucial cultural resource for building, maintaining, legitimating, and ultimately 'scripting' nations and their states (Shapiro 2004: 49). Nationalism, as a type of consciousness, thus draws from narratives of the past to make the fusion of nation and state appear 'natural' (Billig 2009: 17). In that sense, discourses about the past are frequently connected to the construction and maintenance of imagined communities, whether in China (Reilly 2012; Wang 2012) or elsewhere (cf. Gustafsson 2014; Wertsch 2002).

As Wertsch (2002) has pointed out, shared narratives about the past should not be mistaken for 'history'. Whereas history emphasizes that the past is complex, multi-vocal, and open-ended, the kind of narratives that imagined communities draw from are better understood as 'collective remembering' (ibid.: 1047). When societies 'remember' (Halbwachs 1992), they do so dogmatically and without tolerance towards ambiguities; whereas history treats the past as a forum, national remembering treats it as a shrine (Wertsch 2002: 667). 
It can indeed be helpful to call such processes of meaning-making 'collective remembering', particularly considering how members of a community appropriate and internalize shared narrative scripts in ways that at times 'feel' like individual memory. 'What matters', as Guibernau (2004: 135) explains, 'is not chronological or factual history but sentient or felt history'. Nevertheless, 'memory' remains a metaphor. Nations are not persons, and they do not 'remember' like individuals do. Suggesting otherwise risks conflating knowledge of the past and acts of remembering, as is the case in discussions that describe e.g. the lack of knowledge in China about the 1989 Tiananmen Protests as a form of 'amnesia' (Lim 2014). Other authors insist that delegating certain activities, such as writing one's tax returns, constitutes an act of 'outsourcing memory' (Bowker 2005: 257). Such interpretations play fast and loose with the idea of 'remembering'. What such accounts are actually describing, are acts of manipulating information and shaping knowledge, and I find framing the debate in terms of 'mnemonics' ultimately unhelpful for exploring how these processes work. In fact, claims about how nations 'remember' or 'forget', how they have been 'traumatized' or suffer 'amnesia', are themselves discursive moves that deploy the metaphor of personal memory in order to configure historical scripts for political purposes (cf. Wertsch 2002: 553).

A crucial aspect of the nation is thus its discourse of the past, and this discourse is mediated largely through modern mass communication technologies like print, radio, or television (Anderson 2006: 135-140; Billig 2009: ch.5). These one-to-many communication channels have traditionally perpetuated a sense of national community through their use of 
standardized languages and recognisable symbols, regardless of the precise ideological statements that the individual outlets communicated (Gellner 1983/2006: 122). It is thus in no small part the shared experiences with a mediated past that lend the nation its cohesive power. Nation-ness is built into modern mass media.

In China, the Chinese Communist Party (CCP) has embraced the power of mass media early-on and has more recently designing its approach to culture and media governance around the idea of 'public opinion guidance', a concept that creatively fuses Leninist political communication principles and selective media liberalization (Tsang 2009). This approach entails extensive censorship and propaganda efforts alongside collaboration with private actors, and it has been studied in areas such as news media (Stockmann 2013) and broadcasting (cf. my own work in Schneider 2016). It is often argued that the internet challenges this cultural governance approach and empowers contentious users against the Party and state (e.g. Chan \& Bi 2009), and yet the leadership seems fairly effective at retaining its 'guidance' of political discourse across digital realms, whether through its innovative digital censorship system (Deibert et al. 2010: 449-87) or through new forms of propaganda such as 'astroturfing' (i.e. using paid commentators to covertly influence online discussion; cf. Han 2013).

In light of these developments, it seems sensible to ask what role digital media play in the kind of processes that authors like Anderson, Billig, or Gellner have outlined and that East Asia scholars have examined for the case of China. If technologies have particular uses built into them through their designs and arrangements (cf. Winner 1980: 125), then what 
happens, for example, to the history of the nation in that vast repository of human expression that is the web $?^{2}$ Do the interfaces and algorithms of China's web 'programme' a particular kind of discourse about the past?

\section{Searching for the Nanjing Massacre Online}

In societies that have embraced advanced ICT, digital information has become so ubiquitous that it is frequently overwhelming. In 2015, China's webspace encompassed over four million websites with more than two hundred billion individual webpages (CNNIC 2016: 912). To find anything in such an ocean of data, it needs to be filtered so users can retrieve only the information they need. The technology that today achieves this feat is the search engine. Search engines have become the 'switchboards of the internet generation' (Halavais 2009: 1160). They are one of the most important windows through which we access information on the web. Yet search engines are by no means neutral windows onto the web. As König and Rasch (2014: 13) point out:

Search engines function as gatekeepers, channelling information by exclusion and inclusion as well as hierarchization. Their algorithms determine what part of the web we get to see and their omnipresence fundamentally shapes our thinking and access to the world.

Search algorithms distort how knowledge works, raising the question as to how particular digital discourses are prefiltered by search engines, for instance in China. Just like other sectors of China's media ecology, the search engine environment is heavily managed by the Chinese state, which aims to keep foreign services at bay while simultaneously promoting 
carefully monitored domestic alternatives (Shirky 2015: 290). One implication of this strategy is that foreign ICT firms may face sanctions if they do not conform to government requirements like making user data available to the authorities. With regards to search engines, Google avoided this dilemma when it left the PRC market in 2010, ostensibly as a reaction to hacking attempts and censorship issues (Drummond 2010), but likely also because the Californian company found the Chinese market with its home-grown services harder to crack than it had anticipated. Google now offers its Chinese-language services through its Hong-Kong-based URL, but mainland China is effectively a Google-free zone.

Instead, users are offered a number of local search engine alternatives (Jiang 2014). The first and foremost of these is currently Baidu (CNZZ 2014), which led the domestic market with a 56.33 percent share of the 2014 web queries, followed by Qihoo and its ' 360 Search' (at the time of the study called 'Good Search'; Haosou 好搜). Good Search reportedly had a search share of 29.01 percent, trailed by Sohu's 'Search Dog' (Sougou 搜 狗) with 12.75 percent. There are additional search engines in China, including a state-run service called ‘ChinaSo’ (or ‘China Search': Zhongguo suosuo 中国搜索; cf. Jiang \& Okamoto 2014), but none of these attract more than one percent of China's search traffic.

How, then, do mainland Chinese search services like Baidu filter China's conflictladen history with Japan, for instance on a topic like the Nanjing Massacre? To answer this question, I compared the search results for five different search engines in April 2015. Throughout that month, once per week, I systematically queried Baidu.com, Sogou.com, 
Haosou.com, ChinaSo.com, and Google's Chinese-language service Google.com.hk for the Chinese search term 'Nanjing Massacre' (Nanjing datusha 南京大屠杀), using an anonymous 'research browser' (Rogers 2013: 111) and Beijing-based IP addresses (exceptions were the Google queries, for which I simulated the searches from a Hong-Kongbased computer). I have reproduced the search results in the coloured chart in Figure 1 below. Two findings are particularly worth pointing out: the generally strong 'own-content bias' and specifically the high rankings of online encyclopaedias (or baike 百科) affiliated with the search engines.

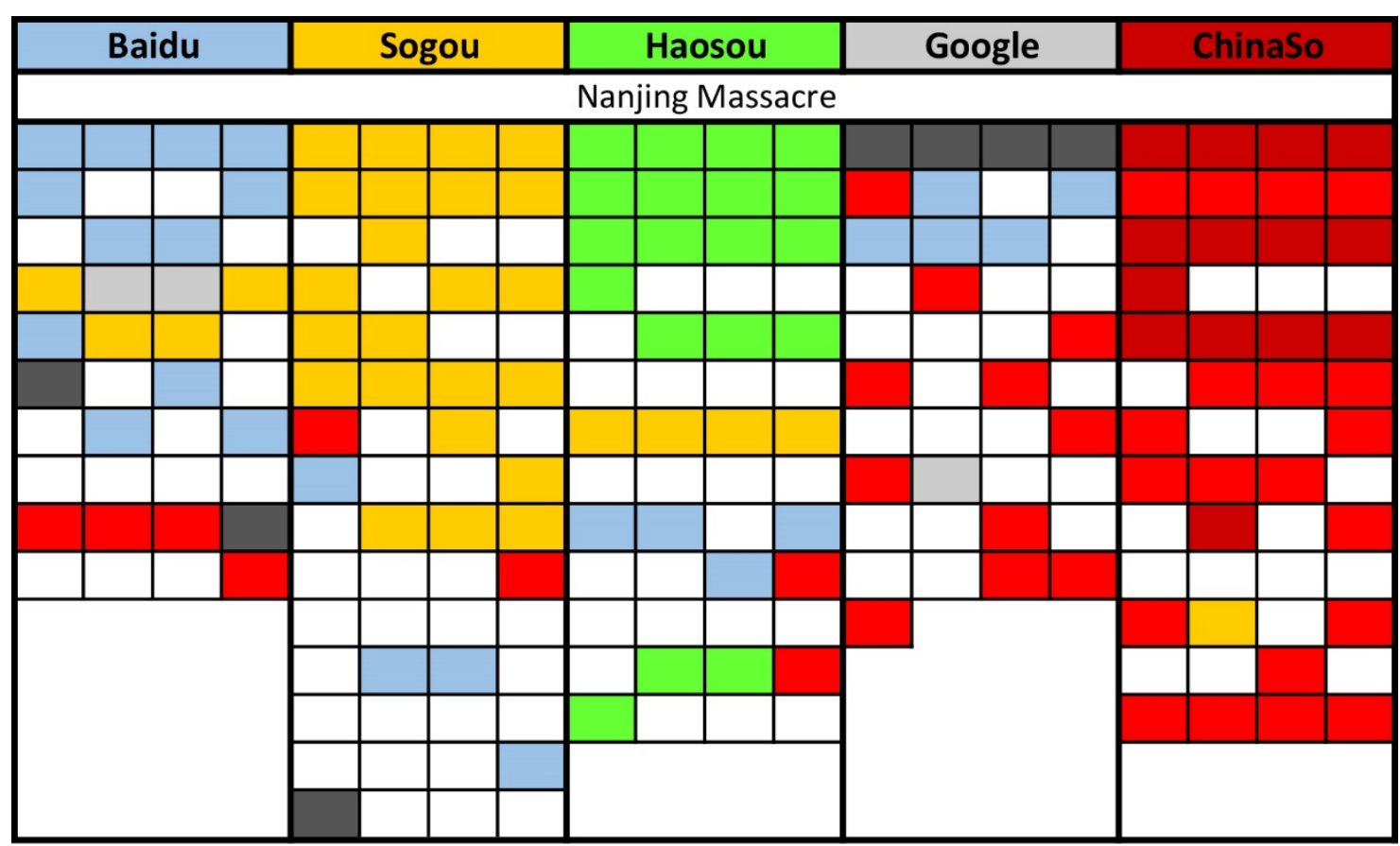

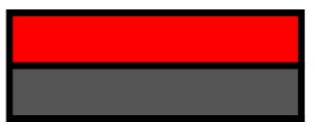

= Official PRC \& CCP Sources

$=$ Wikipedia 
Figure 1. [How different search engines in China produce results on the Nanjing Massacre. Chinese search results for 南京大屠杀 across five search engines. For each search engine, the columns represent different days (weekly queries throughout April 2015). The lines represent search ranks, and the colours represent content associated with the respective company or institution.]

In terms of own-content bias, the various companies show a strong preference for compiling links that keep users inside of their respective digital real estate (cf. also Jiang 2014: 224-6). Baidu consistently lists its own services among the top ranks of the page (30 percent of the time), but its efforts to retain users are surpassed by the practices of its competitors: Search Dog and Good Search each reserve the prime real estate of their results page for in-house content (roughly the first five links 'above the fold' of a standard browser window), and they list affiliated pages 38 and 37 percent of the time, respectively. The results also contain content from other providers, especially links to video-sharing sites like Douban or Youku Tudou and to official CCP or PRC sources (e.g. Xinhua News), but these links were frequently listed at lower ranks. All of the commercial companies were eclipsed by the staterun search engine ChinaSo, which pushed affiliated content 65 percent of the time (27 percent hosted on ChinaSo itself, and 38 percent on allied sources like Xinhua). Content from competing search providers takes a backseat on all mainland Chinese search engines.

The second important observation is that the search engines each promote entries in their own encyclopaedic services at the top of their rankings. Across the four queries, Baidu 
always listed first articles from its ‘Encyclopaedia Baidu’ (Baike Baidu 百科百度). This pattern is mirrored by Search Dog and Good Search, which each privileged their knowledge services ‘Encyclopaedia Search Dog’ (Baike Sogou 百科搜狗) and ‘Encyclopaedia Good Search’ (Baike Haosou 百科好搜), respectively. Moreover, whereas Baidu listed competing knowledge archives like Encyclopaedia Search Dog, Hodong's encyclopaedia (Hudong Baike 互动百科), or Wikipedia in its lower ranks, its competitors rarely did. Search Dog listed the Baidu encyclopaedic entry for 'Nanjing Massacre' for all four searches, but on average placed the link at position twelve out of fifteen. Only once did Search Dog return a Wikipedia entry for the Nanjing Massacre, in the last slot of its results page, and it never listed a Hudong, Good Search, or ChinaSo encyclopaedia entry. As for Good Search, across all queries, the search engine never once listed another encyclopaedia. Interestingly, the only true outlier to these patters was Google, which listed affiliated services only two percent of the time and actually listed more Baidu than Google content.

These findings have important implications: they suggest that users of specific search engines experience the web through very narrow lenses that privilege the contents of the search engine provider and that prevent serendipitous exposure to varied knowledge sources. While users have the option to compare search results across different mainland engines, my own interviews with digital media scholars and practitioners in China (2013-2015) suggests that users rarely go to such troubles, particularly when specific search engines are already installed as the default of their browsers (e.g. Good Search for Qihoo's browser). 


\section{Online Encyclopaedic Knowledge on the Nanjing Massacre}

One of the core resources that search engines point their users towards, are China's Wikipedia-like online encyclopaedias. Scholars of knowledge archives have shown how encyclopaedias can serve as powerful filters of knowledge; they are highly political, for instance by serving implicit conservative or progressive goals through the information they create and the ways they relay it (O'Sullivan 2011). Does it then matter that Chinese search engines prominently direct users to the Nanjing Massacre entries in their in-house encyclopaedias? With each of the mainland Chinese search providers maintaining its own baike, one might expect considerable variation of historical discourses, depending on the search engine that was used to query the topic.

In terms of their knowledge production, the mainland encyclopaedias pride themselves on promoting values that are generally similar to those adopted by Wikipedia, emphasising for example 'verifiability' and 'objectivity'. They also are nominally 'usergenerated', though it is worth keeping in mind that the editorial models differ (cf. Figure 2): whereas Wikipedia relies on openly accessible debates between amateur editors without professional oversight, the mainland encyclopaedias draw their materials from user input but vet these contributions through professional editors, generally in ways that are not open to public scrutiny. They are thus designed to reproduce the logic of traditional publishing with its preference for coherent professional work over potentially inconsistent amateur contents. 
To explore whether these differences in design and editorial practices affect the history discourse on the Nanjing Massacre, I have placed the entries of five Chineselanguage encyclopaedias next to one another and have compared their structure, style of representation, main arguments, and digital features. Indeed, the differences are stark, at least between the Chinese-language Wikipedia entry and its PRC alternatives. Figure 2 shows some of the key features of the encyclopaedias and their entries.

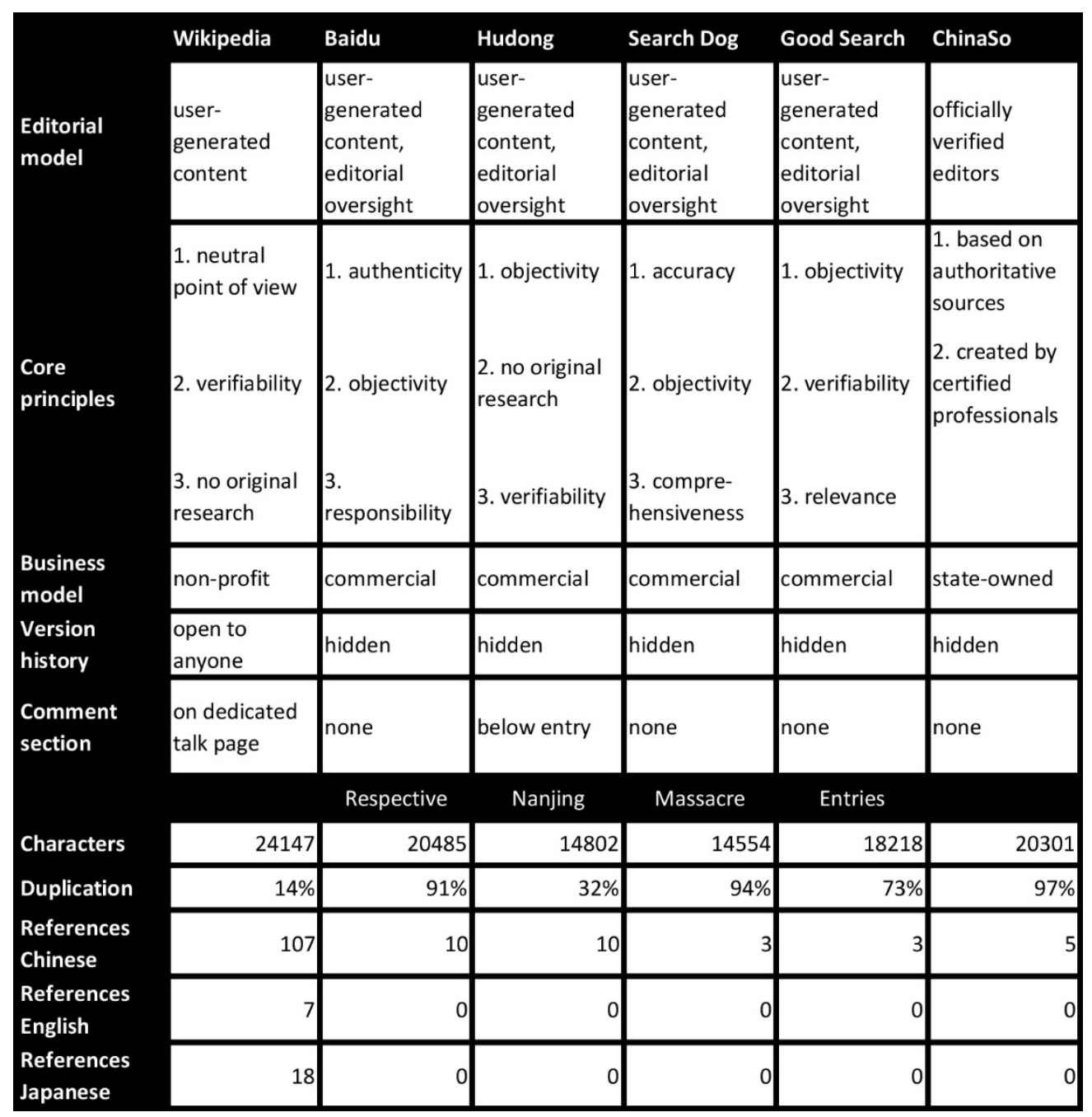


Figure 2. [Online encyclopaedias and the Nanjing Massacre. Key features of Chinese Wikipedia, Encyclopaedias Baidu, Hodong, Search Dog, Good Search, and ChinaSo, for 'Nanjing Massacre' entries, 8 April 2015.]

A few general features are worth highlighting here. Especially noteworthy across the entries is the amount of duplication. Large parts appear in all six encyclopaedias, and Baidu, Search Dog, Good Search, and ChinaSo share a particularly large amount of text. In fact, Search Dog's entry is essentially an abridged version of the Baidu article, and ChinaSo's stateowned offer is almost identical to Baidu's. Since the article histories are only available to registered editors, I am not able to tell who has copied from whom. Considering Baidu's history of plagiarism, and especially of copying Chinese Wikipedia's articles (cf. Nystedt 2006), a plausible scenario is that the editors at the commercial Encyclopaedia Baidu augmented their writing with segments lifted from its non-profit competitor, and that the other Chinese online encyclopaedias then in turn duplicated Baidu's article.

Such a finding is striking, since it calls into question the self-proclaimed values of the Chinese corporations that produce such encyclopaedic entries. The sites proclaim their commitment to originality, yet they are comfortable claiming copyright for entries that are based on extensive plagiarism. This occurs on encyclopaedic sites that all opt to combine user-generated content by registered writers with professional editorial oversight, and yet this added layer of supervision does not appear to affect the degree of duplication that characterizes the content. 
Where the mainland encyclopaedias do not duplicate Wikipedia's content, their style of representation differs markedly from that of the non-profit service. The Chinese Wikipedia entry covers a range of different topics such as the wider context of the Sino-Japanese War, the siege of Nanjing, the various atrocities committed by Japanese soldiers, the cultural and political relevance of the events, etc. Throughout, the article references 122 sources, including academic materials, official documents, news reports, blogposts, and films, in three different languages: English, Chinese, and Japanese. It dedicates substantial space to different positions, and the entry repeatedly complicates the issue and suggests that knowledge on the Nanjing Massacre is no straight-forward matter. For instance, the text discusses the various reasons why evidence for the actual course of events is hard to come by, what different kinds of source materials reveal about the atrocities, and how representations of the Nanjing Massacre in both China and Japan tend to be instrumentalized for political reasons. In a similar vein, the article explores what structural and historical factors may have prompted the Japanese forces to act as they did, and it reviews the attrition, frustration with the war effort, misleading orders, and other contributing factors that may have sparked or at least exacerbated the mayhem in late 1937 Nanjing.

Wikipedia's entry is not without its flaws. Style and quality vary substantially for each section, or even for individual sentences, resulting in an ambiguous patchwork of usergenerated ideas and arguments. This is very much evident in the language: the text switches between simplified and traditional characters, suggesting contributors from different Chinese-language regions, e.g. Taiwan, Hong Kong, overseas communities, and mainland 
China. The style also often changes, for instance from colloquial to highly scholarly language, from literary Chinese to official rhetorical styles. Overall, however, the entry ads substantial nuance to the debate, not to mention a fair amount of Japanese materials. In this sense, it indeed attempts to live up to Wikipedia's ideals of 'neutrality', even if it does so in an uneven way. It is very much an example of the messy sort of knowledge construction that proponents like O’Sullivan (2011) commend.

It remains an open question what readers make of this messiness, and whether they attribute to it the same kind of disruptive, radical potential that O'Sullivan sees. What is demonstrably the case, however, is that this patchwork approach contrasts with the knowledge-making strategies of other Chinese online encyclopaedias. The Chinese services tilt their encyclopaedic model from user-generated amateur content towards professional writing, with user-generated content serving as a labour input to the corporation's commercial endeavours.

The alternative strategy to encyclopaedic knowledge is visible in the Nanjing Massacre discourse that Chinese online encyclopaedias relay. Take the example of Baidu's entry on the subject, which is representative of the other Chinese encyclopaedias and their media logic. Encyclopaedia Baidu provides a much more coherent narrative than Wikipedia, but it mainly achieves this outcome by disambiguating any controversies about the event and by presenting its view of history as factual. Baidu strongly emphasises dates, numbers, and original quotes. Contrary to Wikipedia, Encyclopaedia Baidu does not reflect on the nature of historical knowledge. Its factual information is not accompanied by critical reflections on 
source materials and their value. Instead, the article presents the massacre as a clear-cut case with a singular truth.

This becomes particularly clear when comparing how Baidu and Wikipedia each discuss the Nanjing Massacre's death toll. Both Wikipedia and Baidu include a section that list the various approaches to calculating this death toll, followed by case-to-case figures for various individual atrocities. However, Wikipedia also presents the controversies surrounding such figures. This includes acknowledging how difficult it is to calculate exact numbers, discussing the political symbolism that informs the number 300,000 in the PRC, and a carefully referenced section on different assessments by Japanese scholars that range from 'complete denial' to 'over 200,000' victims.

Baidu does not include similar sections. It instead focuses only on approaches that yield victim counts in excess of 300,000. Importantly, its factual accounts are accompanied by representations of Japan that are suggestive of how this antagonist should be viewed. A lengthy section that presents detailed victim arithmetic, for instance, concludes by presenting an ‘explanation by the Japanese sides’ (Rifang bianjie 日方辩解). It reads: “"The Nanjing Massacre absolutely does not exist, all of these were regular casualties of war" - this has for many years been the explanation that Japan's rightists provide for the atrocities that the invading Japanese troops committed during the Nanjing Massacre' (all translations are mine). Later sections go into greater detail about 'the Japanese side', yet these sections are similarly one-sided: controversies within Japan about such minority views are ignored or are presented 
in ways that leave readers with the impression that Japanese society must be dominated by rightists.

Such commitment to a single point of view extends to the Baidu entry in general, and it is strengthened by recurring sections that are dedicated to 'fact', 'evidence', and 'more irrefutable evidence'. Ironically, these sections then rarely provide verification for their factual claims. Encyclopaedia Baidu is not devoid of references, and the Nanjing Massacre entry specifically mentions a number of historical sources in the main article. It also includes an array of historical photos, some showing historical materials such as Japanese and Chinese newspaper reports from the late 1930s. However, the entry does not provide information that would allow readers to track down the original materials. Whereas Wikipedia's entry frequently provides full bibliographic information, none of the historical materials on Baidu are fully referenced.

Baidu's entry nevertheless references 41 sources, which is still a prolific amount of material, compared to Baidu's competitors: Search Dog and Hudong each list six references and three items for further reading, Good Search's encyclopaedia provides three references, and ChinaSo lists five. However, references point almost exclusively to mainland materials in simplified Chinese. This includes some scholarly materials, but the general emphasis lies with general sources like the Nanjing Massacre Memorial Hall or with recent state-media news reports. 
Overall, the haphazard referencing practices thus clash with the self-proclaimed commitment to 'verifiability'. Surprisingly, the various encyclopaedias have demonstrably mined Wikipedia for text, yet they draw the line at incorporating the reference materials that are provided in the original template. The only exception is Baidu, which makes use of the large fundus of digitized materials that mainland Chinese online archives provide, and which I examine next. Overall, the mainland knowledge aggregators present themselves as professional providers of facts that yield a much more coherent narrative of the past than Wikipedia, albeit based on limited resources and informed by a strong bias.

\section{Digital Depositories of the Past}

When mainland online encyclopaedias showcase or reference historical materials, they frequently draw these from dedicated history websites. To establish how such websites present this historic event, and how they make use of the interactive potential of the web (cf. Pauwels 2005), I have compared and analysed the most prominent cases available on China's web in 2013 (cf. Table 1 in the appendix). What this study shows, is that Chinese Nanjing Massacre websites primarily take an archival approach to history: web portals like Sina's 'Never Forget', the Nanjing Massacre Memorial Hall, or the Global Times' online resources are designed as repositories for historical materials. Many of these materials are digitized versions of documents, testimonials, and pictorial evidence from the 1930s and 1940s, accompanied by academic studies and contemporary news articles. The general editorial 
strategy is to digitize 'offline' materials from accredited sources and showcase these materials online.

The sites generally opt against authoring and designing original articles specifically for the web. When it comes to contemporary news coverage, for instance on Japanese rightwing politicians or on delegations visiting China, the sites overwhelmingly reproduce articles that have appeared in China's state media, thus largely copying verbatim the official discourse and its rhetorical patterns. In short, the Nanjing Massacre websites focus on digital reproduction of officially accredited sources, and they deploy the affordances of the web to this end. Media types like text, image, video, and sound are made to 'converge' on these sites, but at the same time the potential 'hypermediality' (Bolter \& Grusin 2000) of the web is scaled back. The websites hardly ever include in-text links, instead reproducing the noninteractive text blocks of traditional print media.

In cases where sites do provide hyperlinks, these links rarely lead off-site. Source materials from other institutions include reference text at the bottom, but these references do not link to original digital articles. All sources are reproduced locally. The general practice is then to provide a lengthy list of links on the homepage, often accompanied by images and teaser texts, and to have these links direct users to full-text digitized articles at a local subdomain, which seem designed as endpoints of the user's journey. The links are programmed to open in new browser tabs or windows, which means they do not provide the kind of seamless 'travel' across materials that web scholars originally associated with hyperlinking (Manovich 2001: 76). 
Entering these digitized archives quickly becomes overwhelming: at the time of the study, Sina's portal, which is by far the largest, contained 1765 posts, including 716 images and 65 video clips. Other archives or link libraries, for instance the Nanjing Massacre Memorial Hall's homepage or the military affairs sites Leiting (literally 'thunderbolt') and Tiexue (i.e. 'iron blood'), were much smaller, yet they still offered hundreds of posts. However, the scope of such information archives should not be overstated. The homepages suggest a vast amount of diverse information across different categories, yet despite often differing titles, many of the individual articles are duplicates, causing users to repeatedly cycle through the same materials. My study of the posts in Sina's Never Forget archive, for instance, suggested that roughly one third of the articles were redundant. Articles and images had often been uploaded twice or more, frequently to unique URL addresses. Sina thus implies that its archive is much larger than it actually is.

It is not just the number of posts that leave such an impression. A particularly subtle way in which Sina exaggerates its scope is visible on its commemoration site, which allows users to post a symbol of mourning together with a comment. According to the information at the bottom of each page, the site had collected 768,601 individual comments. However, only the first 50 of the ca. 76,000 webpages contained original comments. From page 51 onwards, all pages were simply copies of page 50 . Without speaking to the web editors, it is unclear what the rationale behind this duplication was (a technical reason, a strategic choice, or an oversight), but the effect is that users enter a seemingly huge interactive space that is actually quite small. 
This leads me to another point: how the sites limit interactions and channel user content into recognizable scripts. Most of the sites have their comment function disabled, so that users cannot post messages underneath the articles. The only voices are those of the authors, many of whom are professional journalists. Where websites allow user comments, for instance on the Sina commemoration site or on the military portal Tiexue, the default mode of such commentary is righteous indignation and anger. Comments frequently draw from racist tropes like ‘dogs’ (gou 狗) or ‘foreign devils’ (guizi 鬼子), and it is popular to demand that all Japanese be killed in retribution for the massacre.

It is noteworthy that these inflammatory racial defamations are not deleted by the authorities or the website providers, despite the effectiveness of the PRC's censorship system (cf. Deibert et al. 2010: 449-487). In the case of the website Tiexue, many of the most aggressive statements are in fact sanctioned by a virtual red 'stamp' that marks comments as particularly 'popular replies' (remen huifu 热门回复), based on the number of 'likes’ they received from other users. I have reproduced one such instance in Figure 3. This comment to a post on Tiexue about rape during the Nanjing occupation suggests that anyone killing a Japanese person should receive 1000 RMB, and it concludes with the words 'kill kill kill ...'. While this is an exceptionally crude comment (not all comments are aggressively racist), it was ranked highest by 'likes'. The 'popular response' stamp is visible in the top right corner. Interactive algorithmic mechanisms thus create the impression that racist outrage is indeed an appropriate or even praiseworthy response to the event. There are also website sections that 
promote mutual respect between China and Japan, for instance Japanese peace delegations visiting Nanjing, and likewise the comment sections also contain conciliatory remarks, yet such sentiments are comparatively rare and seem marginalized by the more chauvinistic statements that design choices and algorithmic factors 'push' to the fore.

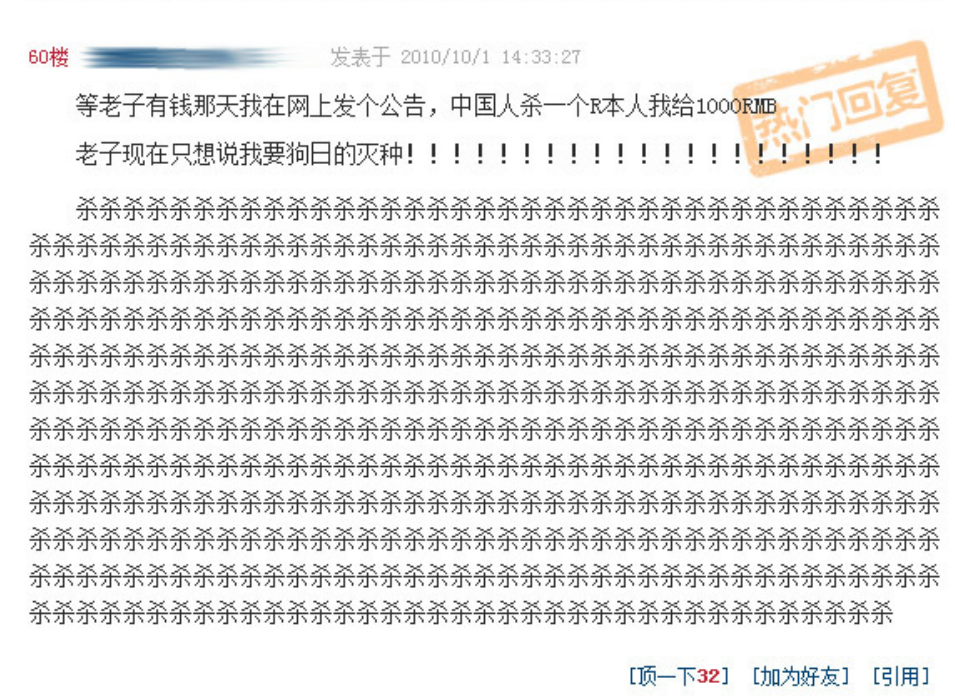

Figure 3. [Sanctioning anti-Japanese anger on China's web. User comment on the message board Tiexue.net; screenshot taken on 15 May 2013.]

What is more, the user comments seamlessly tie in with the recognizable, highly emotive signs that the Nanjing Massacre websites regularly deploy. This includes animated Chinese flags, symbols of peace, and a host of symbols associated with mourning, but also icons or effects with violent connotations. The website China918.net, for instance, uses sniper crosshairs as bullet points for its section headers. An early version of the Nanjing Massacre Memorial Hall's website included a banner with the Nanjing city wall, animated in a way 
that would periodically drench the wall in rivers of blood. The Chinese University of Hong Kong (one of two non-mainland website in the pool of sources, neither of which substantially challenged the overarching discourse) uses a similar visual trope, overlaying an image of the Nanjing Massacre Memorial's walls with red blotches. The sites thus make use of a recognizable fundus of emotive symbols, of 'pathos tropes' (Müller \& Kappas 2011), which are then stacked to drive home one particular emotional interpretation in different modes.

The link collection on the Communist Youth League website is such an example: it juxtaposes a text full of national humiliation tropes with patriotic red colour, exclamation marks, animations of emotive slogans, and flashing red flames, all the while playing a musical score that combines monumental revolutionary songs and melodramatic traditional themes with fervent movie quotes. It is thus not too surprising when web portals that allow user interaction do not sanction aggressively emotional remarks; after all, their own representations of the event are often similarly aggressive. The overarching theme is that of a humiliated nation that will forever need to remember its suffering at the hands of 'little Japan’ (xiao Riben 小曰本), a derogatory phrase that recurs throughout the discourse.

What this website analysis then suggests, is that the dedicated web archives that present the Nanjing Massacre on China's web are informed by a specific idea of what history is. In contrast to other understandings of history (e.g. White 1987), the past is here not a complex, multi-vocal, and open-ended process of meaning-making in which historical facts possess the meanings attributed to them in the present. Instead, history is treated as one grand 
narrative, as a continuous movement 'forward' through time, in which historical facts tell us what is true or false about the past and how to feel about this. In other words, the Nanjing Massacre discourse on China's web treats the past as a shrine rather than as a forum for discussion. Its use of the web's technological affordances reflects this, and this is also visible in the resulting network structures.

\section{Hyperlink Infrastructures of National Humiliation}

The technical and editorial choices of web editors also affect how information on the Nanjing Massacre is structured on the web. This becomes apparent when mapping out the part of China's web that contains the history websites. To see what kind of website networks the discourse is embedded in, I used an open-access analytical programme called the IssueCrawler to trace the hyperlinks through which Nanjing Massacre websites pointed to web resources. The process was then refined by looking for links at different levels of remove (also called the 'degree'), which each have distinct implications; the second level of remove is generally used to track so-called 'issue networks' (Rogers 2013): systems of connections between actors with dense interactions, which are frequently indicators of some shared concern (for discussions cf. Bruns 2007 and my own arguments in Schneider 2015).

Do Chinese Nanjing Massacre web resources tie into such an 'issue network'? The analysis reveals that the websites do not form anything that could be legitimately interpreted as such a system of similar concerns. I have already mentioned above how modest the 
respective websites are in their use of hyperlinks, and the effects of this practice are indeed visible in this part of China's web. The various sites do not normally link to one another. This does not mean they are not situated within larger networks, but simply that these larger networks have little to do with the Nanjing Massacre. Instead, the analysis reveals that the topic is located in what Bruns (2007) calls a 'secondary issue network', in which sites link to one another due to very broad topical or institutional communalities.

A crawl of the Nanjing Massacre websites produces a 'secondary issue network' very early on, at the first level of remove from the original source websites. A 'first degree' network of 'co-links' (suggesting communities of websites) consisted of 80 nodes. Processing the data through the open-source network visualization programme Gephi makes it possible to highlight additional features. For instance, two of the starting pages that are retained at this stage (the pages by the Chinese University of Hong Kong and the website on Sina.com) are not actually connected to the network, but remain outside the general structure as single 'isolates'. This means that they received at least two links from the original starting pages, but do not link to each other or the other nodes in the network, and are consequently not part of anything resembling a 'community'. Another five starting points are indirectly represented, for instance through associated higher-level pages (such as homepages for general news sites), but the original issue pages are no longer part of the co-linked network at this level of analysis. I have visualized this network in Figure 4 below. 


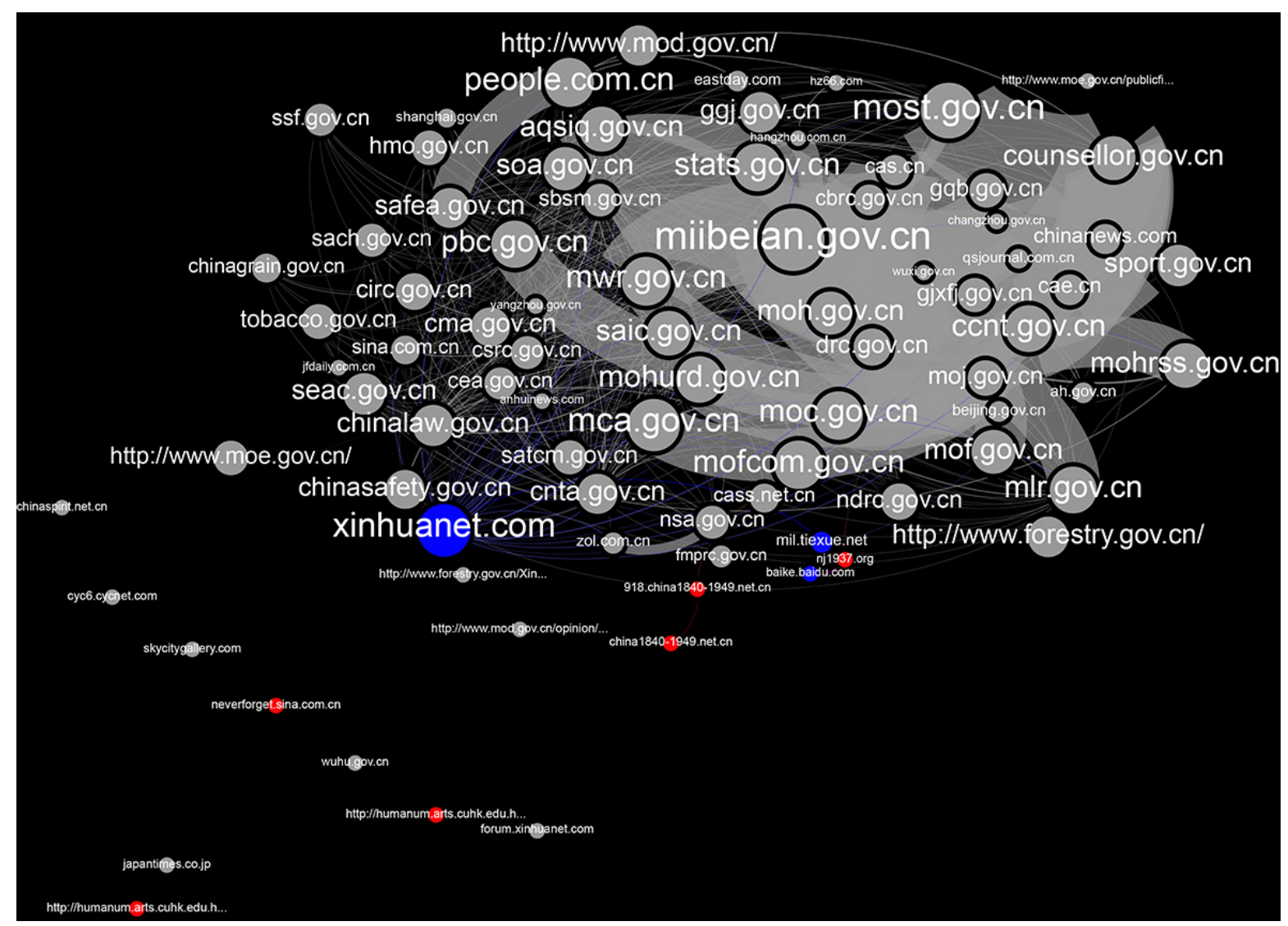

Figure 4. [Immediate neighbourhood of the Nanjing Massacre issue pages. Node size represents eigenvector centrality, thickness of lines (edges) represents the number of links, colours represent starting points (crawl depth $=2$, iterations $=1$; algorithm: force atlas). Network data collected on 3 May 2013.]

Once the analysis is expanded to include an additional iteration, the picture changes dramatically. Only one issue page is still loosely included in this 100 -node network (the news service China Economic Net). Other original starting points are merely associated with the network through their parent sites (e.g. Xinhua.net or Sina.com). Yet others are missing 
entirely at this stage, including large sites like Encyclopaedia Baidu. The 'issue' has essentially disappeared.

In this extended network, the majority of nodes represent large, institutionalized players. In the immediate neighbourhood of the original issue pages, this includes several websites that have dot-com extensions but are actually run by the state or Party, such as Xinhua, the People's Daily, or China News. These nodes tend to be more 'authoritative' than others, meaning they receive links from sources that likewise receive many links (as network analysists put it, they possess a high 'eigenvector centrality'; Goldbeck 2013: 988). The network also includes dot-com commercial sites, as well as academic, military, or CCP actors. However, the overwhelming majority of nodes are clearly marked as government entities through their dot-gov-dot-cn URL extensions. I have visualized this network in Figure 5 by colour-coding the different domain extensions and resizing the nodes according to their authority within the network.

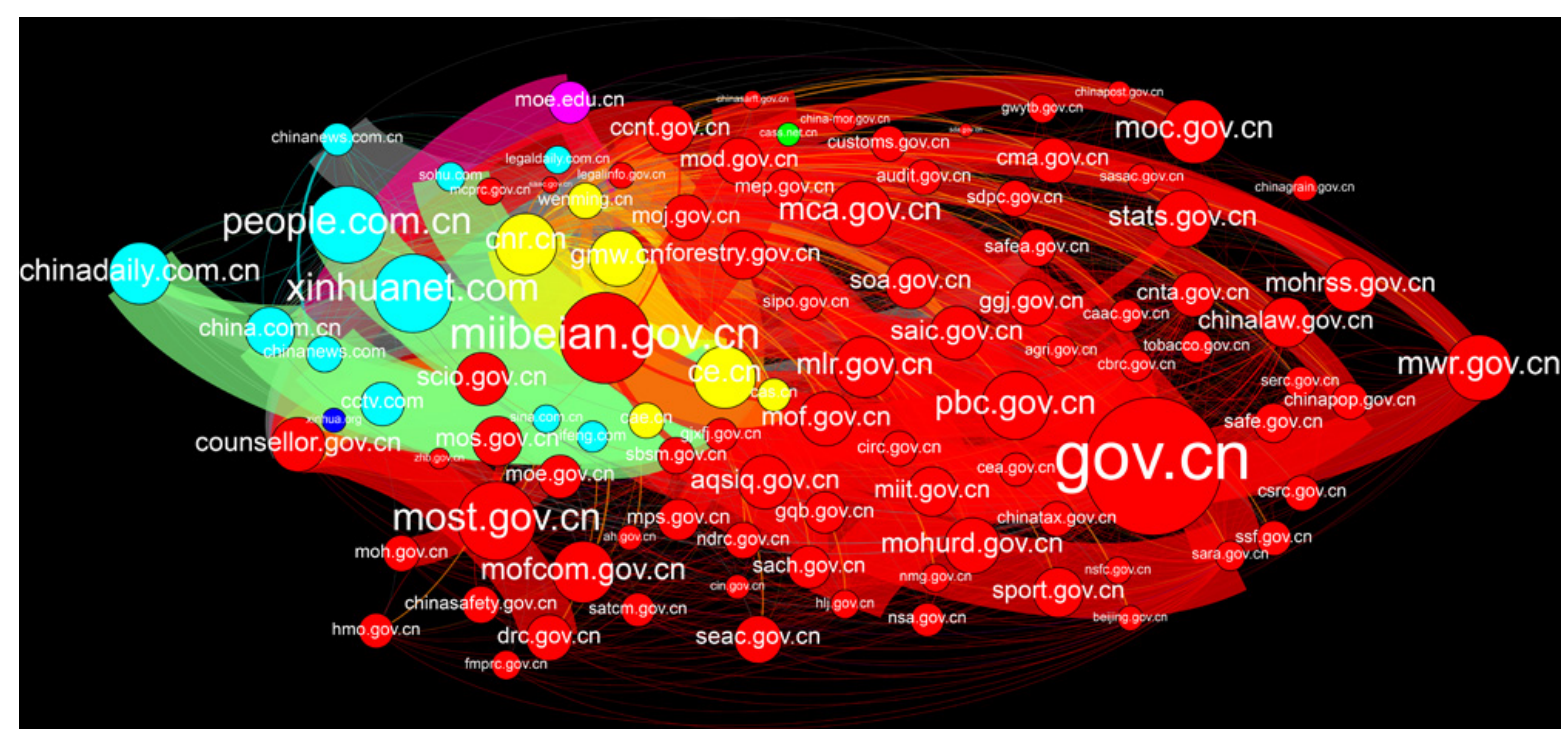


Figure 5. [Extended network of the Nanjing Massacre issue pages. Node size represents eigenvector centrality, thickness of lines (edges) represents the number of links, colours represent domain types (crawl depth $=2$, iterations $=2$; algorithm: force atlas). Network data collected on 3 May 2013.]

The graphical representation highlights an important feature: that state actors dominate the network. In fact, the most important actor is the Chinese government, represented centrally by the State Council's website www.gov.cn. Government sites generally amass the most references from other authoritative nodes, and based on this criterion the two most authoritative actors are the State Council and the Ministry of Information Industries (miibeian.gov.cn), which is the institution responsible for managing the Chinese internet.

The Nanjing Massacre web discourse is thus embedded in an online space that is dominated by state and Party actors. The reasons for this do not lie solely in the policy choices that the state and its ruling Party make (e.g. decreeing who can authoritatively present content online and shutting down websites that offend official guidelines), though such governance practices certainly play an important role in structuring China's online spaces. That said, the present hyperlink study draws attention to two additional factors that shape web discourses: the design and content choices that web editors make (e.g. when to link to other web sources) and the way that the technology of the web works (e.g. rewarding sources that receive many references with ever more references). The in-built 'hypermediality' of the web can thus be reconfigured to resemble the traditional mass-media networks that the CCP prefers for its political communication efforts, and these recalibrated 
web networks lend themselves to the unified, national historiography that I have discussed here.

\section{Conclusion}

This article has examined an important national history discourse on China's web: the Nanjing Massacre. Tracing the discourse through China's search engines, online encyclopaedias, major websites, and hyperlink networks, this study finds that the Nanjing Massacre's history resides within a national media ecology dominated by sources that relay a singular, definitive narrative on the issue while discouraging interaction, ambiguity, and serendipity. This creates a particular 'media logic' (Chadwick 2013) that starts with China's search engines and extends to mainland online encyclopaedic entries, which generally eschew the kind of 'see-for-yourself' culture that user-generated content could potentially facilitate (Benkler 2006: 218). This logic further shapes the archival practices of large web repositories, with their digitized official content and lack of user interaction, and it is visible in the way the Nanjing Massacre's hyperlink networks are structured to create a hierarchical info-web, dominated by state and Party institutions. Throughout these networks, web editors and writers deploy pathos to frame accounts of the past, disambiguating the historical narrative by driving its morale home in overlapping modes of communication (textually, visually, and acoustically). The web resources leave little doubt as to how particular elements 
of the historical accounts should correctly be 'felt', and the default mode is a sense of deeprooted humiliation and righteous anger.

In short, as far as the Nanjing Massacre discourse is concerned, China's web provides a framework for making sense of the past as a national shrine rather than a forum, bringing it in line with official narratives. This is not to say that the online discourse is solely chauvinistic. While official media support patriotic sentiments, Chinese leaders are also wary of radical nationalism (Gries et al. 2016: 177), and websites associated with the Party or state at times indeed showcase conciliation rather than humiliation, for instance when depicting Sino-Japanese cases of cultural exchange. In such moments, history starts to resemble a forum. Yet even where websites describe transnational exchanges at eye-level, they do not engage in them through the web's potential to create discussion. Voices from outside China are rare and only appear either in support of the domestic consensus or as targets of righteous vitriol. Comment sections are either disabled or provide users with spaces to comment in ways that are rarely interactive, and that are overall shaped by the same emotive scripts that also inform nationalist discourse more generally.

It may seem unsurprising that a politically sensitive web discourse in China remains relatively homogenous. After all Chinese media are traditionally under close Party and state scrutiny, and China's authorities have long integrated media discourses into their 'patriotic education campaign', which intentionally flattens the complexities of the past (Wang 2012; Callahan 2010). However, the web’s 'hypermediality’ (Bolter \& Grusin 2000) could potentially encourage the kind of serendipity that would counter efforts to homogenize 
discourses. And yet, in the case of China's web, the technical affordances of the medium have become arranged to facilitate the kind of media logic that the CCP prefers, which is a traditional mass-media logic. The present, media-centric study suggests that this outcome has as much to do with technical and design elements built into China's web as with regulatory choices aimed at preserving the CCP's mass-media rationale. This interaction between technology and politics lends itself to the shrine-like representation of history on which nationalism relies, in China or elsewhere. Authors like Anderson and Gellner suggest that nation-ness may be built into mass media. In the Chinese case, the CCP's efforts to calibrate China's web in line with its own interests assure that nationalism is also built into digital media.

What we are left with is the uncomfortable impression that an important piece of modern Chinese historiography is constructed on the PRC's web in ways that do not do justice to the complexity of the human past. Future studies will need to explore whether similar processes are at work in other national webs, e.g. in Japan, and how these findings compare to practices in often vibrant social media spheres, which I have not examined here. Recent research suggests that Sino-Japanese discourse in China's social media is characterized by highly diverse discussions (Feng \& Yuan 2014). As research on history and memory suggests, no single actor 'owns' a discourse once that discourse is opened to such discussion (Evans 2003: 12): 'Historians may be hard at work redesigning the past, however, but so too are politicians, painters, novelists, sculptors, movie-makers, television producers, 
textbook writers, teachers, museum directors and a whole host of other people, and what comes out as the end result may not be quite what any of them intended'.

Despite this caveat, I would contend that even where the meaning of the nation is up for debate, its nature rarely is. Nationalism is a form of consciousness that creates meaning by prompting members of the nation to see the world through the lens of communities that are imagined as politically and culturally cohesive. As Billig (2009: 55) has argued, the resulting worldviews do not separate into distinct positive 'civic' vs negative 'chauvinistic' attitudes - a distinction that is itself often ideological. The core of nationalism remains an imagined sense of group attachment, and all groups are constructed around 'some features that make them special and, in a certain way, "superior" to the rest' (Guibernau 2004: 137). For national communities, a unified historiography is precisely such a feature.

It is with these considerations in mind that we should re-evaluate the potential of digital media to redefine or even unhinge feelings of nation-ness. This study suggests that as far as the web is concerned, digital media do not necessarily challenge the rationale of traditional media, but can extend them to reproduce nationalism in similar ways. Digital networks, with their propensity to lock users into like-minded sub-networks (Pierson 2014), are ideal allies to established mass communication channels, particularly in a country like China where the political leadership tries to recalibrate digital networks under the banner of 'national sovereignty'. Indeed, the PRC's media and cultural governance approach under Xi Jinping has heavily focused on bringing all media, traditional or new, in line with the Party's 
preferred media logic, and within this logic, digital media become well suited for the kind of comfort-zone maintenance on which nationalism relies.

In the end, the potential of certain digital media configurations to inspire myopic views and feelings does not bode well for disputes such as those over modern East Asia's history. As long as such disputes are framed through nationalism, they remain anchored in false dichotomies (e.g. us vs them), attribution errors (e.g. to what exactly feelings like loyalty or hatred should be attached), and dogmatic commitment to specific narrative accounts (e.g. victimization or heroic superiority). These dimensions of imagined communities are ultimately inimical to the prospect of meaningful historical reconciliation.

\section{Acknowledgement}

The research for this article was made possible through a VENI grant from the Netherlands Organization of Scientific Research (project no. 275-63-005). I would like to thank my colleagues at Leiden University for their support during the course of that project, as well as the participants of the 2015 and 2016 international conferences on media and history in East Asia, organized by Barak Kushner and Rana Mitter at Cambridge University, for their feedback. Finally, I am grateful to the JAS editorial team and the anonymous peer-reviewers of this article for their helpful advice on the manuscript. All shortcomings in this article are of course entirely my own. 


\section{List of References}

Anderson, Benedict. 2006. Imagined Communities, 3rd rev. ed. London \& New York: Verso.

BenKLeR, YochaI. 2006. The Wealth of Networks - How Social Production Transforms Markets and Freedom. New Haven and London: Yale University Press.

Berry, David M. 2011. The Philosophy of Software: Code and Mediation in the Digital Age. London et al.: Palgrave Macmillan.

BILlig, MiCHAEL. 2009. Banal Nationalism, 9th ed. London et al.: SAGE.

BOLTER, DAVID \& GRUSIN, RICHARD. 2000. Remediation - Understanding New Media. Cambridge MA: MIT Press.

Bowker, GeOFFreY. 2005. Memory Practices in the Sciences. Cambridge MA \& London: MIT Press.

BRUNS, AXEL. 2007. "Methodologies for Mapping the Political Blogosphere: An Exploration Using the IssueCrawler Research Tool". First Monday 12(5): http://eprints.qut.edu.au/7832/1/7832.pdf (accessed December 10, 2017).

Callahan, William A. 2010. China - The Pessoptimist Nation. Oxford: Oxford University Press.

CNNIC. 2016. "Statistical Report on Internet Development in China (January 2016)". China Internet Network Information Centre Online, https://cnnic.com.cn/IDR/ReportDownloads/201604/P020160419390562421055.pdf (accessed December 10, 2017).

CNZZ. 2014. 'Suosuo yinqing shiyong qingkuang fenxi baogao' (Report on Search Engine Usage), http://engine.data.cnzz.com/ (accessed January 29, 2016).

Chadwick, ANDrew. 2013. The Hybrid Media System - Politics and Power (Kindle ed.). Oxford: Oxford University Press.

Chan, Evelyn \& Bi, Chenggeng. 2009. "The Internet and State Media: The 4.5 Estate". China Elections and Governance Review 3: 1-15.

Deibert, Ronald, PALFRey, John, RoHOzinski, RAFAL, \& ZitTrain, JonAthan, eds. 2010. Access Controlled: The Shaping of Power, Rights, and Rule in Cyberspace, Cambridge MA: MIT Press.

Denton, KIRK A. 2014. Exhibiting the Past-Historical Memory and the Politics of Museums in Postsocialist China. Honolulu: University of Hawai'i Press.

Drummond, DAVID. 2010, March 22. “A New Approach to China: An Update”. Google Official Blog, https://googleblog.blogspot.n1/2010/03/new-approach-to-chinaupdate.html (accessed December 10, 2017)

Esarey, Ashley \& Qiang, XiaO. 2008. "Political Expression in the Chinese Blogosphere: Below the Radar". Asian Survey 48(5): 752-772.

Evans, Richard J. 2003. "Introduction: Redesigning the Past: History in Political Transition". Journal of Contemporary History 38(1): 5-12. 
Feng, Miao \& Yuan, Elaine J. 2014. "Public Opinion on Weibo: The Case of the Diaoyu Island Dispute". In The Dispute Over the Diaoyu/Senkaku Islands: How Media Narratives Shape Public Opinion and Challenge the Global Order, ed. Thomas A. Hollihan, 119-40. New York: Palgrave MacMillan.

Fogel, JoshuA A., ed. 2000. The Nanjing Massacre in History and Historiography. Berkeley: University of California Press.

GELLNER, ERNEST. 1983/2006. Nations and Nationalism. New York: Blackwell.

GOLDBECK, JENNIFER. 2013. Analyzing the Social Web (Kindle ed.). Amsterdam et al.: Morgan Kaufmann.

Gries, Peter, Steiger, Derek, \& WAng, TaO. 2016. "Social Media, Nationalist Protests, and China's Japan Policy: The Diaoyu Islands Controversy, 2012-13”. In The Internet, Social Meida, and a Changing China, eds Jacques De Lisle, Jacques, Avery Goldstein, \& Guobin Yang, 161-79. Philadelphia: University of Pennsylvania Press.

Guibernau, MontSERrAT. 2004. "Anthony D. Smith on Nations and National Identity: A Critical Assessment". Nations and Nationalism 10(1/2): 125-41.

Guibernau, MontSERrAT. 2013. Belonging: Solidarity and Division in Modern Societies. Cambridge \& Malden, MA: Polity Press.

Gustafsson, KARL (2014), 'Memory Politics and Ontological Security in Sino-Japanese Relations'. Asian Studies Review, 38(1), 71-86.

HAgSTRÖM, LINUS. 2012. "'Power Shift' in East Asia? A Critical Reappraisal of Narratives on the Diaoyu/Senkaku Islands Incident in 2010". The Chinese Journal of International Politics 5: 267-297.

Halavais, AleXANDER. 2009. Search Engine Society (Kindle ed.). Cambridge \& Malden, MA: Polity.

Halbwachs, Maurice. 1992. On Collective Memory. Chicago \& London: University Of Chicago Press.

Han, RongBin. 2013. “Adaptive Persuasion in Cyberspace: The 'Fifty Cents Army' in China". Paper Submitted for the 2013 Annual Meeting of the America Political Science Association.

HE, YinAN. 2007. "History, Chinese Nationalism and the Emerging Sino-Japanese Conflict". Journal of Contemporary China 16(50): 1-24.

Herold, David Kurt \& Marolt, Peter, eds. 2011. Online Society in China: Creating, Celebrating, and Instrumentalising the Online Carnival. London \& New York: Routledge.

JiAnG, Min. 2014. "The Business and Politics of Search Engines: A Comparative Study of Baidu and Google's Search Results of Internet Events in China". New Media \& Society 16(2): 212-233.

JiAnG, Min \& OKAMOTO, KRISTEN. 2014. "National Identity, State Ideological Apparatus, or Panopticon? A Case Study of Chinese National Search Engine Jike". Policy \& Internet, 6(1), 89-107. 
Kingston, JEFF. 2007. “Awkward Talisman: War Memory, Reconciliation and Yasukuni”. East Asia 24(3): 295-318.

KÖNIG, RENÉ \& RASCH, MIRIAM, eds. 2014. Society of the Query Reader - Reflections on Web Search. Amsterdam: Institute of Network Cultures.

LEIBOLD, JAMES. 2010. "More Than a Category: Han Supremacism on the Chinese Internet". China Quarterly 203: 539-59.

Lim, LouISA. 2014. The People's Republic of Amnesia: Tiananmen Revisited. Oxford: Oxford University Press.

LIU, Jun. 2014. "Mobile Communication and Relational Mobilization in China". Asiascape: Digital Asia 1(1-2): 14-38.

ManOVICH, LeV. 2001. The Language of New Media. Cambridge MA: MIT Press.

MÜLLER, MARION G. \& KAPPAS, ARVID. 2011. "Visual Emotions - Emotional Visuals. Emotions, Pathos Formulae, and their Relevance for Communication Research". In The Routledge Handbook of Emotions and the Mass Media, eds Katrin Doveling, Christian von Scheve, and Elly A. Konijn, 310-31. Oxford: Routledge.

NystedT, DAN (2006, August 6), "Wikipedia Attacks Chinese Search Engine". PC Advisor, http://www.pcadvisor.co.uk/news/internet/wikipedia-attacks-chinese-search-engine-

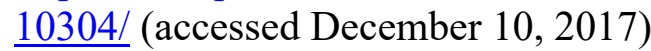

O’Sullivan, DAN. 2011. 'What is an Encyclopedia? A Brief Historical Overview from Pliny to Wikipedia'. In Critical Point of View: A Wikipedia Reader, eds Geert Lovink and Nathaniel Tkacz. INC Reader No.7, 34-49. Amsterdam: Institute of Network Cultures.

PARISER, Eli. 2012. The Filter Bubble: How the New Personalized Web Is Changing What We Read and How We Think (Kindle ed.). New York et al.: Penguin Books.

PAUWELS, LuC. 2005. "Websites as Visual and Multimodal Cultural Expressions: Opportunities and Issues of Online Hybrid Media Research". Media Culture Society 27(4): 604-613.

Pierson, EMmA. 2014. "See How Red Tweeters and Blue Tweeters Ignore Each Other on Ferguson". Quartz, November 25, 2014, http://qz.com/302616/see-how-red-tweetersand-blue-tweeters-ignore-each-other-on-ferguson/ (accessed December 10, 2017).

ReILly, JAMES. 2012. Strong Society, Smart State: The Rise of Public Opinion in China's Japan Policy. New York: Columbia University Press.

Rogers, RichARD. 2013. Digital Methods. Cambridge MA: MIT Press.

SAAler, Sven. 2005. Politics, Memory and Public Opinion: The History Textbook Controversy and Japanese Society. Munich: Deutsches Institut fur Japanstudien.

SCHNEIDER, FLORIAN. 2015. "Searching for 'Digital Asia' in its Networks: Where the Spatial Turn Meets the Digital Turn”. Asiascape: Digital Asia 2(1-2): 56-91.

SCHNEIDER, FLORIAN. 2016. "The Cultural Governance of Mass Media in Contemporary China”. In Handbook of Cultural and Creative Industries in China, ed. Michael Keane, 189-206. Cheltenham \& Northampton, MA: Edward Elgar.

SHAPIRO, MiCHAEL J. 2004. Methods and Nations: Cultural Governance and the Indigenous Subject. New York \& London: Routledge. 
Shen, Simon \& Breslin, Shaun, eds. 2010. Online Chinese Nationalism and China's Bilateral Relations. Lanham: Lexington.

Shirky, Clay. 2015. Little Rice: Smartphones, Xiaomi, and the Chinese Dream (Kindle ed.). New York: Columbia Global Reports.

Stockmann, Daniela. 2013. Media Commercialization and Authoritarian Rule in China (Kindle ed.). Cambridge: Cambridge University Press.

SuZUKi, TAKeSHI \& MURAI, SHUSUKE. 2014. "How the Japanese Legacy Media Covered the Senkaku Controversy". In The Dispute Over the Diaoyu/Senkaku Islands: How Media Narratives Shape Public Opinion and Challenge the Global Order, ed. Thomas A. Hollihan, 141-68. New York: Palgrave MacMillan.

TONG, JingRONG \& ZUO, LANDONG. 2014. "Weibo Communication and Government Legitimacy in China: A Computer-Assisted Analysis of Weibo Messages on Two 'Mass Incidents"'. Information, Communication \& Society 17(1): 66-85.

Tsang, Steve. 2009. “Consultative Leninism: China's New Political Framework”. Journal of Contemporary China 18(62): 865-80.

Wallace, Jeremy \& Weiss, Jessica CHEN. 2015. "The Political Economy of Nationalist Protest in China: A Subnational Approach". China Quarterly 222: 403-29.

WANG, ZHENG. 2012. Never Forget National Humiliation - Historical Memory in Chinese Politics and Foreign Relations. New York: Columbia University Press.

Wertsch, JAmes V. 2002. Voices of Collective Remembering. Cambridge: Cambridge University Press.

White, HAyden. 1987. The Content of the Form: Narrative Discourse and Historical Representation. Baltimore: The Johns Hopkins University Press.

Winner, Longdon. 1980. “Do Artifacts have Politics?” Daedalus 109(1): 121-36.

YAng, GuOBIn. 2009. The Power of the Internet in China-Citizen Activism Online. New York: Columbia University Press.

ZHANG, ZHAN. 2014. "Fanning the Flames of Public Rage: Coverage of Diaoyu Islands Dispute in the Chinese Legacy Media". In The Dispute Over the Diaoyu/Senkaku Islands: How Media Narratives Shape Public Opinion and Challenge the Global Order, ed. Thomas A. Hollihan, 81-118. New York: Palgrave MacMillan.

Zheng, Yongnian. 2008. Technological Empowerment - The Internet, State, and Society in China. Stanford: Stanford University Press. 


\section{Appendix}

Table 1: Chinese Nanjing Massacre websites (compiled summer 2013)

\section{Notes}

${ }^{1}$ A common criticism of Anderson's argument is that his focus on 'imagination' turns the nation into a set of immaterial, symbolic interactions, thereby denying how national politics are demonstrably grounded in real institutions, material production processes, and lived experiences. Who, for instance, would deny that a person held up at a nation-state border is 'imagining' their plight? However, this criticism is founded in both a slippage between the idea of the nation and the nation-state (discussed in Guibernau 2004) and a misrepresentation of Anderson's premise. Anderson (2006: 6) was specific that 'communities are to be distinguished, not by their falsity/genuineness, but by the style in which they are imagined'.

${ }^{2}$ I have focuses solely on the web in this article and have bracketed social media. The rationale is that the web constitutes the early, basic backbone of internet information infrastructures, and that examining its workings can provide a sense of how digital media can 
become re-calibrated by certain actors. Whether a similar form of re-calibration is taking place on social media will have to remain the focus of future studies. 